\title{
Quantifying the effect of land use and land cover changes on green water and blue water in northern part of China
}

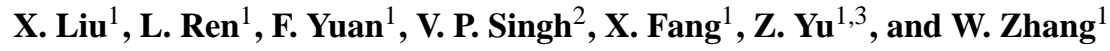 \\ ${ }^{1}$ State Key Laboratory of Hydrology-Water Resources and Hydraulic Engineering, College of Hydrology and Water \\ Resources, Hohai University, No. 1 Xikang Road, Nanjing 210098, China \\ ${ }^{2}$ Dept. of Biological \& Agricultural Engineering, Texas A \& M University, 2117 Tamu, College Station, \\ Texas 77843-2117, USA \\ ${ }^{3}$ Dept. of Geoscience, University of Nevada Las Vegas, Las Vegas, Nevada 89054, USA
}

Received: 9 July 2008 - Published in Hydrol. Earth Syst. Sci. Discuss.: 29 August 2008

Revised: 14 May 2009 - Accepted: 14 May 2009 - Published: 12 June 2009

\begin{abstract}
Changes in land use and land cover (LULC) have been occurring at an accelerated pace in northern parts of China. These changes are significantly impacting the hydrology of these parts, such as Laohahe Catchment. The hydrological effects of these changes occurring in this catchment were investigated using a semi-distributed hydrological model. The semi-distributed hydrological model was coupled with a two-source potential evaportranspiration (PET) model for simulating daily runoff. Model parameters were calibrated using hydrometeorological and LULC data for the same period. The LULC data were available for 1980, 1989, 1996 and 1999. Daily streamflow measurements were available from 1964 to 2005 and were divided into 4 periods: 1964-1979, 1980-1989, 1990-1999 and 2000-2005. These periods represented four different LULC scenarios. Streamflow simulation was conducted for each period under these four LULC scenarios. The results showed that the change in LULC influenced evapotranspiration (ET) and runoff. The LULC data showed that from 1980 to 1996 grass land and water body had decreased and forest land and crop land had increased. This change caused the evaporation from vegetation interception and vegetation transpiration to increase, whereas the soil evaporation tended to decrease. Thus during the period of 1964-1979 the green water or ET increased by $0.95 \%$, but the blue water or runoff decreased by $8.71 \%$ in the Laohahe Catchment.
\end{abstract}

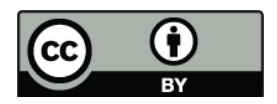

Correspondence to: L. Ren

(rll@hhu.edu.cn)

\section{Introduction}

Blue water is the visible liquid water moving above the ground as surface runoff and below the ground as groundwater runoff (FAO, 1995b; Falkenmark and Rockstrom, 2004). Blue water can thus be in the form of surface runoff in rills, gullies or rivers, or water stored in reservoirs and lakes, or water flowing underground, recharging water tables and aquifers. Green water is defined as the invisible vapor moving to the atmosphere (FAO, 1995a; Falkenmark and Rockstrom, 2004), including productive green water defined as transpiration from plants and trees, and nonproductive green water consisting of soil evaporation and vegetation interception evaporation. Green water thus equates the commonly used term ET, which combines productive and nonproductive vapor in one term. It is a new concept to partition water into blue water and green water, which may effectively be utilized to study the effect of LULC changes on the catchment water balance.

Quantification of the effect of LULC changes on the partition of blue water and green water of a river basin has been of interest to hydrologists in recent years. However, the conversion of rainfall into runoff is complex and our understanding of the quantitative relationship between the LULC properties and runoff generation mechanism is far from complete.

The effect of LULC changes on the hydrological processes is mainly contributed by the changes in vegetation interception, soil evaporation, plant transpiration, infiltration and soil water content, and the consequent changes in the partition of rainfall into blue water and green water. In earlier studies, the assessment of the impact of LULC changes on runoff was done mainly through field experiments. There are many reviews of these experiments in the literature, notably those

Published by Copernicus Publications on behalf of the European Geosciences Union. 


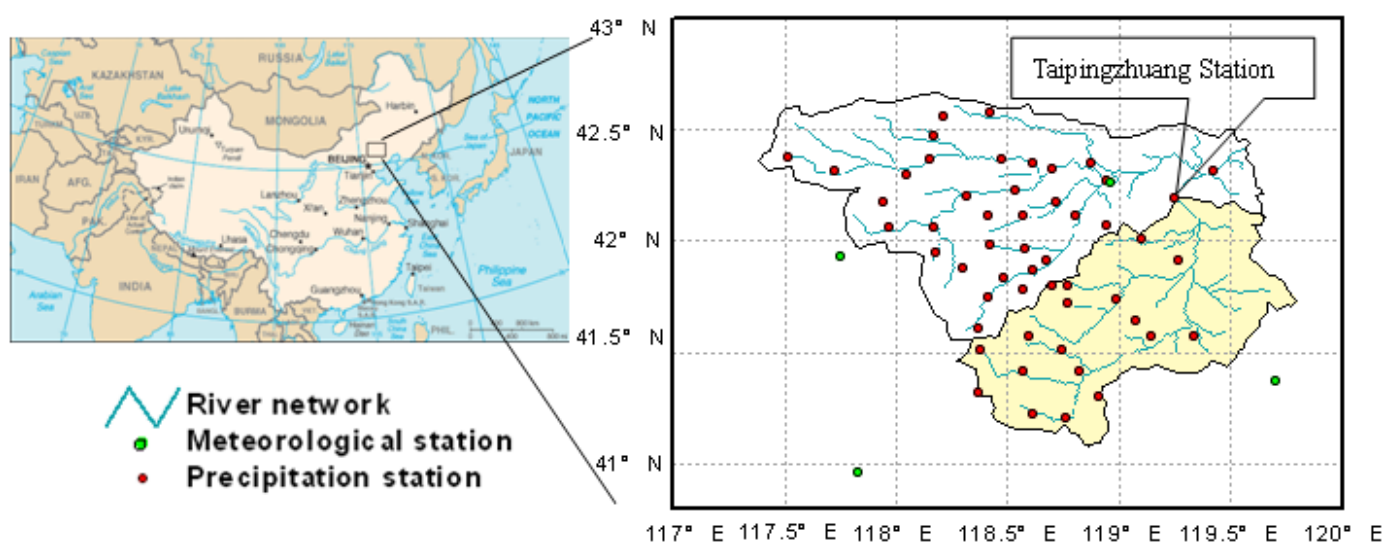

Fig. 1. The location of Laohahe Catchment.

of Hibbert (1967); Hollis (1975); Bosch and Hewlett (1982); and Zhang et al. (1999). These studies, which generally indicate that deforestation causes an increase in the mean annual discharge, have concentrated on the impacts of forest management on water yield (Siriwardena et al., 2006). While field experiments can conclusively demonstrate the consequences of LULC changes, modeling studies often provide more insight into the flow mechanisms and processes. Based on precise input data and accurate model structure, hydrological models have the capability of addressing the impact of LULC changes on various hydrological processes.

Nowadays, hydrological models are being used to address the impact of LULC changes. Lorup et al. (1998) calibrated lumped models for a reference period when there is a little change in LULC and applied it to a subsequent period in which changes in LULC have taken place. They carried out a trend analysis of the bias between modeled and observed runoffs to investigate the changes in catchment runoff that might arise due to the LULC changes. Wilk et al. (2001) calibrated a daily rainfall-runoff model for the pre-clearing period and then used it to predict the catchment yield after clearing. They were unable to detect any hydrological change that could be attributed to the reduction in forest cover. They attributed this to the fact that the LULC changes were not uniform across the catchment and there were a significant number of trees remaining on agricultural land and secondary re-growth on agricultural plots. Chen et al. (2004) applied a distributed hydrological model SWAT to simulate the rainfall-runoff relationship of the Suomo basin under different LULCs in order to evaluate the impact of LULC changes on runoff, ET and peak stream flow. They found that if LULC changed from a non-vegetation-cover to a full-forest-cover scenario, the runoff depth (blue water) decreased and evaporation (green water) increased. With the same recurrent flood flow, the peak stream flow value under the full-forest-cover scenario was $31.2 \%$ less than that under the non-vegetation-cover scenario.

The objective of this study was to investigate the effect of
LULC changes on the hydrological processes in the Laohahe Catchment in northern China by using a semi-distributed hydrological model coupled with a two-source PET model. Using the direct evaporation from the intercepted water, potential canopy transpiration and potential soil evaporation as the input to the semi-distributed hydrological model, the effect of LULC changes on the ET process was quantified. Four LULC scenarios derived from satellite images were used to represent the vegetative cover over the catchment during four periods: 1964-1979, 1980-1989, 1990-1999 and 20002005, respectively. Model parameters were calibrated using hydrometeorological and LULC data corresponding to the same periods. The effect of LULC changes was then investigated by applying the calibrated hydrological model to three other LULC scenarios.

\section{Study area and data preparation}

\subsection{Description of the study area}

The Laohahe Catchment is located in the semi-arid region of northern China and has a drainage area of $7.720 \mathrm{~km}^{2}$, with the Taipingzhuang hydrological station $\left(42^{\circ} 12^{\prime} \mathrm{N}, 119^{\circ} 15^{\prime} \mathrm{E}\right)$ at the catchment outlet (Fig. 1). The river across the basin is the upstream tributary of the Laohahe River. Elevation within the catchment ranges from $444 \mathrm{~m}$ to $1836 \mathrm{~m}$ above mean sea level, with elevation declining from southwest toward northeast. There are 19 rain gauges, 4 meteorological stations and 1 hydrological station (Taipingzhuang) in this basin and the recorded data are available from 1964 to 2005 . Annual average maximum (minimum) temperature is $14^{\circ} \mathrm{C}\left(2^{\circ} \mathrm{C}\right)$ ranging from $-4^{\circ} \mathrm{C}\left(-16^{\circ} \mathrm{C}\right)$ in January to $29^{\circ} \mathrm{C}\left(18^{\circ} \mathrm{C}\right)$ in July. The average annual precipitation is approximately $451 \mathrm{~mm}$, and the spatial and temporal distribution of precipitation is uneven. About $88 \%$ of the annual precipitation occurs from May through September. 
Agriculture and stock raising are the main productive activities within the Laohahe Catchment, thus grassland and cropland are the dominant types of land use. The main driving forces of LULC changes were population growth in the region and local/national development policy, in order to meet the food requirement. For example, due to the underdeveloped economy and lack of food in 1960's, the government of China encouraged the people to develop agriculture and enlarge the area of cropland to solve the starvation problem. In the 1990's, the people found the reclamation could cause many environmental problems, such as soil erosion, inundation, and environmental pollution. Thus the government revised its policies to protect the forest land and encouraged the farmers to transfer the cropland into forestland or grassland. Since 1949, there have been four periods of large-scale reclamations in the catchment. However the conversion of cropland to forestland or grassland was also progressing at the same time.

\subsection{Data preparation}

\subsubsection{Topography}

The digital elevation model (DEM) data (Fig. 2) within $40.9^{\circ} \sim 42.9^{\circ} \mathrm{N}$ and $117.2^{\circ} \sim 120^{\circ} \mathrm{E}$ at the spatial resolution of $30 \mathrm{~s}$ by $30 \mathrm{~s}$ were obtained from the Global Land Onekilometer Base Elevation database (Yuan, 2006). The digital elevation drainage network model (Martz and Garbrecht, 1992) was used to generate the river network and catchment boundary automatically.

\subsubsection{LULC data}

Four scenarios of LULC maps (Fig. 3) at the spatial scale of DEM were derived from satellite images and were available to represent the vegetative cover over the catchment during the period of 1964-2005. These LULC maps were interpreted from Landsat MSS, TM and ETM+ images with a variety of reference data.

According to the reference data, reliable samples of each class were selected cautiously, whose separability was computed. All the Jeffries-Matusita and Transformed Divergence data measuring the separability were above 1.98, which means the samples had reliable separability (Richards, 1999). Specific spectral characteristics of samples were analyzed, respectively, especially at red, near-infrared and shortwave infrared bands. Concretely, water body showed very low reflectivity at the shortwave infrared band, while urban and built-up land showed high reflectivity at the shortwave infrared band. And vegetation showed high reflectivity at near infrared but low reflectivity at the red band. Furthermore, different threshold values of near-infrared reflectivity and simple ratio (Person and Miller, 1972) were explored to classify vegetation into 3 types: forest, grass and crop. The decision tree classification method was used here based on the above

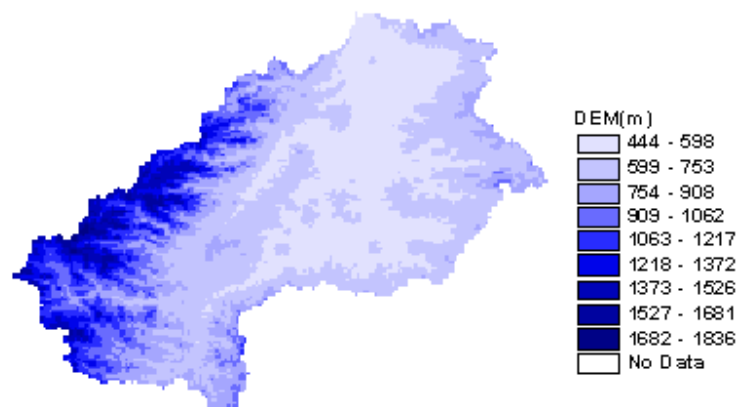

Fig. 2. Digital elevation map of the studied area.
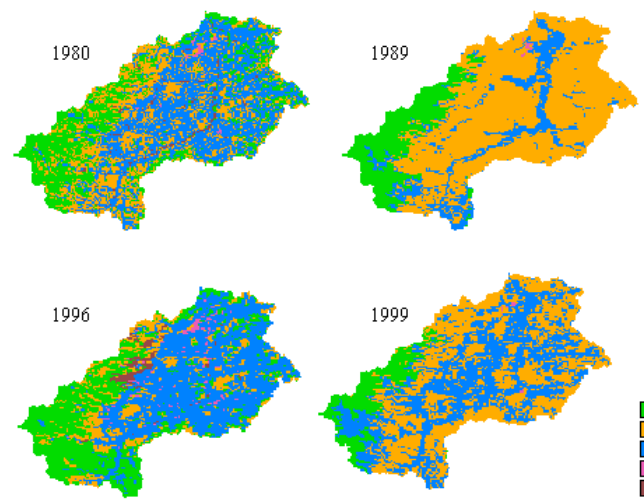

Forest land Grass land crop land urban an others

Fig. 3. Four LULC maps in Laohahe Catchment.

analyzed spectral characteristics and the spatial patterns of land cover classes. Post-classification refinements were applied to reduce classification errors caused by the similarities in spectral responses of certain classes. All the user's and producer's accuracies of the classification were respectively above $87.7 \%$ and $86.9 \%$, and the overall accuracies were above $90.6 \%$, and Kappa statistic were above $90.9 \%$.

\subsubsection{NDVI data}

The NOAA-AVHRR NDVI dataset is available monthly for the globe at a spatial resolution of $8 \mathrm{~km}$, during the period from July 1981 to September 2001, except for the datamissing period from September to December of 1994. The NDVI data within the studied area were clipped according to the basin boundary and transferred into the resolution of $30 \mathrm{~s}$.

\subsubsection{Meteorological data}

The required meteorological data include daily mean, maximum and minimum air temperatures, air vapor pressure, wind velocity, daylight duration and precipitation. In this study, daily precipitation data were measured at 19 raingauged stations covering the whole studied area, and the other meteorological data were observed at 4 meteorological 
stations around the catchment. All meteorological data were interpolated over the whole study area using the inverse distance square method (Ashraf et al., 1997). Based on DEM, such meteorological variables as air temperature, air vapor pressure and wind velocity were topographically corrected with the empirical relationships during interpolation:

$T_{a}=-0.586 Z_{100}+T_{\mathrm{obs}}$

$e_{a}=e_{\mathrm{obs}} \exp \left(-0.0507 Z_{100}\right)$

$u_{a}=u_{\mathrm{obs}}\left\{3.6-2.6 \exp \left(-0.0569 Z_{100}\right)\right\}$

Where $T_{a}, e_{a}, u_{a}$ are the air temperature $\left({ }^{\circ} \mathrm{C}\right)$, air vapor pressure $(\mathrm{kPa})$ and wind speed $\left(\mathrm{m} \mathrm{s}^{-1}\right)$ in a grid cell, respectively; $Z_{100}$ is the altitude difference between the grid cell and meteorological station in $100 \mathrm{~m}$; and the quantities $T_{\mathrm{obs}}, e_{\mathrm{obs}}$, $u_{\text {obs }}$ are the air temperature $\left({ }^{\circ} \mathrm{C}\right)$, air vapor pressure $(\mathrm{kPa})$ and wind speed $\left(\mathrm{m} \mathrm{s}^{-1}\right)$ records at the meteorological station, respectively.

\section{Model description}

\subsection{Two-source PET model}

ET is a process of water vapor transfer from the soilvegetation system to the atmosphere, including interception evaporation, soil evaporation, and plant transpiration. PET is generally considered to be the amount of water which would be lost to the atmosphere from a land surface where water is enough to satisfy the atmospheric evaporation demand.

Mo et al. (2004) developed a two-source ET model based on the Penman-Monteith equation for actual evapotranspiration (AET):

$E_{c}=\frac{\Delta R_{n c}+\frac{\rho C_{p} D_{0}}{r_{a c}}}{\lambda\left[\Delta+\gamma\left(1+\frac{r_{c}}{r_{a c}}\right)\right]}\left(1-W_{f r}\right)$

$E_{s}=\frac{\Delta\left(R_{n s}-G\right)+\frac{\rho C_{p} D_{0}}{r_{a s}}}{\lambda\left[\Delta+\gamma\left(1+\frac{r_{s}}{r_{a s}}\right)\right]}$

$E_{i}=\frac{\Delta R_{n c}+\frac{\rho C_{p} D_{0}}{r_{a c}}}{\lambda(\Delta+\gamma)} W_{f r}$

where $E_{c}, E_{s}$ and $E_{i}$ are the canopy transpiration, soil evaporation, and evaporation from the intercepted water, respectively; $R_{n c}$ and $R_{n s}$ are the net radiation absorbed by canopy and soil $\left(\mathrm{W} \mathrm{m}^{-2}\right)$, respectively; $G$ is the soil heat flux $\left(\mathrm{W} \mathrm{m}^{-2}\right) ; \lambda$ is the latent heat of vaporization $\left(\mathrm{MJ} \mathrm{kg}^{-1}\right) ; \rho$ is the air density $\left(\mathrm{kg} \mathrm{m}^{-3}\right) ; C_{p}$ is the air specific heat at con-

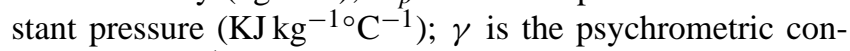
stant $\left(\mathrm{kPa}^{\circ} \mathrm{C}^{-1}\right) ; \Delta$ is the first-order derivative of saturation vapor pressure with temperature $\left(\mathrm{kPa}^{\circ} \mathrm{C}^{-1}\right) ; W_{f r}$ is the wetted fraction of the canopy; $r_{c}, r_{s}, r_{a c}$ and $r_{a s}$ are the bulk stomatal resistance of canopy, soil surface resistance, bulk

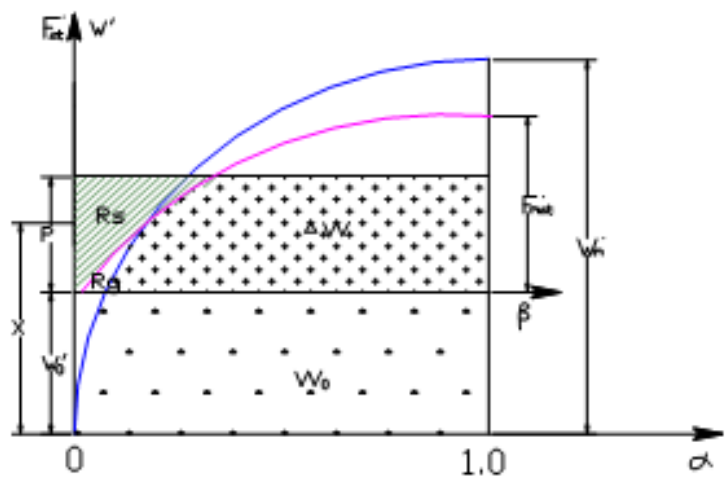

Fig. 4. Basic concept of HYB

boundary-layer resistance of the canopy, and aerodynamic resistance between the soil surface and canopy air space, respectively $\left(\mathrm{s} \mathrm{m}^{-1}\right)$; and $D_{0}$ is water vapor deficit at the source height $(\mathrm{kPa})$.

For calculating the PET consisting of potential canopy transpiration, potential soil evaporation and direct evaporation from the intercepted water, Yuan (2006) improved the two-source ET model:

$$
\begin{aligned}
& E_{p c}=\frac{\Delta R_{n c}+\frac{\rho C_{p} D_{0}}{r_{a c}}}{\lambda\left[\Delta+\gamma\left(1+\frac{r_{c p}}{r_{a c}}\right)\right]}\left(1-W_{f r}\right) \\
& E_{p s}=\frac{\Delta\left(R_{n s}-G\right)+\frac{\rho C_{p} D_{0}}{r_{a s}}}{\lambda\left[\Delta+\gamma\left(1+\frac{r_{s p}}{r_{a s}}\right)\right]}
\end{aligned}
$$

where $E_{p c}$ is the potential canopy transpiration, $E_{p s}$ is the potential soil evaporation, $r_{c p}$ is the bulk stomatal resistance of canopy while the soil moisture at field capacity $\left(\mathrm{s} \mathrm{m}^{-1}\right)$, and $r_{s p}$ is the soil surface resistance while the soil moisture at field capacity $\left(\mathrm{s} \mathrm{m}^{-1}\right)$. In this study, $r_{s p}=300 \mathrm{~s} \mathrm{~m}^{-1}$.

The method of calculating evaporation from the intercepted water is the same as Eq. (6). The detailed parameterization schemes of radiation balance, land surface resistance and interception in the two-source PET model can be referred to the paper by Yuan et al. (2008).

The evaporation from water surface estimated by substituting the aerodynamic resistance of Penman wind speed function and $r_{s}=0$ into P-M equation (Shuttleworth, 1993) was also considered in this study:

$$
\mathrm{ET}=\frac{\Delta}{\Delta+\gamma} 0.408\left(R_{n}-G\right)+\frac{\gamma}{\Delta+\gamma} 2.624\left(1+0.536 u_{2}\right)\left(e_{s}-e_{a}\right)
$$

where $e_{s}$ and $e_{a}$ are the saturation and actual vapor pressures $(\mathrm{kPa})$, respectively; and $u_{2}$ is the wind speed $\left(\mathrm{m} \mathrm{s}^{-1}\right)$ at $2 \mathrm{~m}$ height. 


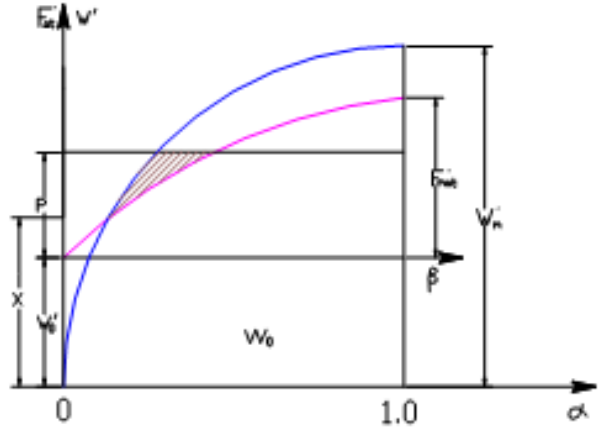

(a)

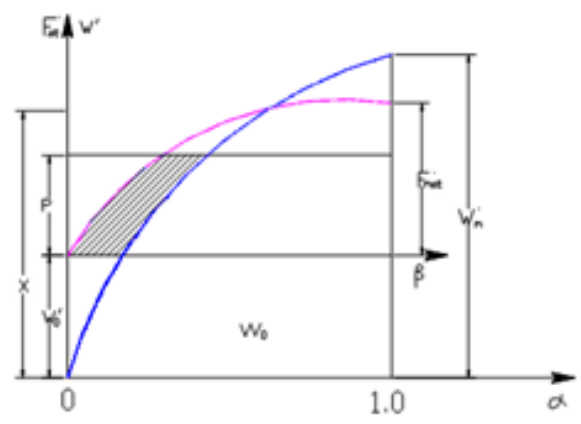

(b)

Fig. 5. Two examples explaining the concept of HYB.

\subsection{Hydrological model}

\subsubsection{Basic concept of hybrid runoff model}

PET was used to drive a semi-distributed hydrological model based on a grid of $30 \mathrm{~s}$. The ET component was represented by a model of three soil layers (Zhao, 1992). Runoff generation was based on a hybrid runoff model (Hu, 1993; Hu, et al., 2005), denoted by HYB, and runoff routing was carried out using the Muskingum-Cunge method.

Numerous field studies show that runoff within a basin is mainly generated by two mechanisms: infiltration excess (Horton) runoff and saturation excess (Dunne) runoff. The hybrid runoff model combines the two runoff mechanisms by means of the combination of spatial distribution curve of soil tension water storage capacity and that of infiltration capacity. This is the way by which daily runoff simulation was conducted in the Laohahe Catchment.

The basic concept of the hybrid runoff model can be expressed as shown in Fig. 4. The blue curve represents the distribution curve of soil tension water storage capacity regarding the alpha axis as the abscissa. For a catchment, the distribution curve of soil tension water storage capacity is unique. The pink curve represents the distribution curve of soil infiltration capacity regarding the beta axis as the abscissa. The distribution curve of soil infiltration capacity is not unique, which is related to the soil moisture content. So the two curves meet in different fields or do not meet for different values of soil moisture content and precipitation.

The basin is spatially divided by the distribution curve of soil tension water storage capacity into two parts, $\alpha$ and $(1-\alpha)$. The rainfall over the sub-area, $\alpha$, all becomes runoff, including surface runoff and groundwater runoff. Over the other sub-area, $(1-\alpha)$, runoff cannot be produced until the soil tension water storage equals field capacity. In the process of soil moisture content up to its field capacity, surface runoff may be possibly generated when rainfall intensity exceeds infiltration rate over a partial area where soil moisture does not reach its field capacity. That partial area is shown as the shaded area in Fig. 5a. The distribution curve of the tension water storage capacity can be written as follows:

$\alpha=1-\left(1-\frac{W^{\prime}}{W_{m}^{\prime}}\right)^{B}$

where abscissa variable $\alpha$ denotes the proportional fraction of the pervious area in the whole basin, in which tension water storage capacity is equal to or less than the ordinate value, $W^{\prime}$. $W_{m}^{\prime}$ is the maximum value of tension water capacity ( $\mathrm{mm}$ ) at a point within the studied basin. Parameter $B$ is the exponential of the parabolic curve. Following Zhao (1980), the areal mean tension water capacity $W_{m}$ can be expressed as:

$W_{m}=\frac{W_{m}^{\prime}}{1+B}$

The basin is spatially segmented by the distribution curve of soil infiltration capacity into two parts, $\beta$ and $(1-\beta)$. Surface runoff is produced over the partial area, $\beta$, when rainfall intensity exceeds infiltration rate; runoff cannot be generated over the other area, $(1-\beta)$, for the rainfall intensity is less than the infiltration rate. However, in spite of weak rain intensity, runoff would probably be generated over the partial area of $(1-\beta)$, where soil moisture content has reached its field capacity. That partial area is represented as the shaded area in Fig. 5b. The Horton infiltration curve was adopted for the computation of infiltration rate at any point within the basin, which can be expressed as:

$f_{t}=f_{c}+\left(f_{0}-f_{c}\right) e^{-k t}$

where $f_{t}$ is the point value of infiltration rate $(\mathrm{mm} / \mathrm{h})$ at time $t$; $f_{0}$ is the maximum infiltration rate $(\mathrm{mm} / \mathrm{h})$; and $f_{c}$ the static infiltration constant $(\mathrm{mm} / \mathrm{h})$ at a surface point; and $k$ is decay coefficient with time. The spatial distribution curve 
of infiltration quantity during the time step of $\Delta t$ can be expressed as:

$\beta=1-\left(1-\frac{F_{\Delta t}^{\prime}}{F_{m \Delta t}^{\prime}}\right)^{B X}$

where variable $\beta$ is the fraction of an area for which infiltration quantity is equal to or less than $F_{\Delta t}^{\prime} ; F_{\Delta t}^{\prime}$ and $F_{m \Delta t}^{\prime}$ are the point values of infiltration quantity $(\mathrm{mm})$ and the maximum infiltration quantity $(\mathrm{mm})$ in the duration of $\Delta t$, respectively; and $B X$ is the shape parameter. The average spatial infiltration quantity, $F_{m \Delta t}$, similar to the case of tension water capacity, can be computed as:

$F_{m \Delta t}=\frac{F_{m \Delta t}^{\prime}}{1+B X}$

\subsubsection{Runoff generation calculation of HYB}

It is supposed that $P$ is precipitation (subtracting evaporation at the same time) during the time interval of $\Delta t ; W_{0}$ is the initial soil tension water storage in millimeter. Then runoff can be computed according to the relationship amongst $P$, $W^{\prime}{ }_{m}, W^{\prime}{ }_{0}+F^{\prime}{ }_{m \Delta t}$, and the intersection point of the two distribution curves introduced above. The flow chart of runoff computation in HYB is shown in Fig. 6.

1. There is a point of intersection between the two distribution curves if $W^{\prime}{ }_{0}+F^{\prime}{ }_{m \Delta t} \leq \mathrm{W}_{m}^{\prime}$. It is assumed that $x$ represents the ordinate of that point of intersection. Runoff computation could be made in the following three cases.

a) When $\left(P+W_{0}^{\prime}\right) \leq x$,

$R_{s}=P-F_{m \Delta t}\left[1-\left(1-\frac{P}{F_{m \Delta t}^{\prime}}\right)^{B X+1}\right]$

$R_{g}=F_{m \Delta t}\left[1-\left(1-\frac{P}{F_{m \Delta t}^{\prime}}\right)^{B X+1}\right]-\left(W_{m}-W_{0}\right)$

$+W_{m}\left(1-\frac{W_{0}^{\prime}+P}{W_{m}^{\prime}}\right)^{B+1}$

b) When $x<P+W_{0}{ }^{\prime} \leq W_{0}{ }^{\prime}+F^{\prime}{ }_{m \Delta t}$,

$R_{S}=P-F_{m \Delta t}\left[1-\left(1-\frac{P}{F_{m \Delta t}^{\prime}}\right)^{B X+1}\right]$

$R_{g}=F_{m \Delta t}\left[1-\left(1-\frac{x-W_{0}^{\prime}}{F_{m \Delta t}^{\prime}}\right)^{B X+1}\right]-\left(W_{m}-W_{0}\right)$

$+W_{m}\left(1-\frac{x}{W_{m}^{\prime}}\right)^{B+1}$

c) When $P+W_{0}{ }^{\prime}>W_{0}{ }^{\prime}+F_{m \Delta t}^{\prime}$,
$R_{s}=P-F_{m \Delta t}$

$R_{g}=F_{m \Delta t}\left[1-\left(1-\frac{x-W_{0}^{\prime}}{F_{m \Delta t}^{\prime}}\right)^{B X+1}\right]-\left(W_{m}-W_{0}\right)$

$+W_{m}\left(1-\frac{x}{W_{m}^{\prime}}\right)^{B+1}$

2. There is no intersection point between the two distribution curves when $W_{0}^{\prime}+\mathrm{F}_{m \Delta t}^{\prime}>\mathrm{W}_{m}^{\prime}$. Runoff computation may be made in the following three other cases.

d) When $P+W_{0}^{\prime} \leq W_{m}^{\prime}$,

$R_{s}=P-F_{m \Delta t}\left[1-\left(1-\frac{P}{F_{m \Delta t}^{\prime}}\right)^{B X+1}\right]$

$R_{g}=F_{m \Delta t}\left[1-\left(1-\frac{P}{F_{m \Delta t}^{\prime}}\right)^{B X+1}\right]-\left(W_{m}-W_{0}\right)$

$+W_{m}\left(1-\frac{W_{0}^{\prime}+P}{W_{m}^{\prime}}\right)^{B+1}$

e) When $W_{m}^{\prime}<P+W_{0}^{\prime} \leq W_{0}^{\prime}+F_{m \Delta t}^{\prime}$,

$R_{S}=P-F_{m \Delta t}\left[1-\left(1-\frac{P}{F_{m \Delta t}^{\prime}}\right)^{B X+1}\right]$

$R_{g}=F_{m \Delta t}\left[1-\left(1-\frac{P}{F_{m \Delta t}^{\prime}}\right)^{B X+1}\right]-\left(W_{m}-W_{0}\right)$

f) When $P+W_{0}^{\prime}>W_{0}^{\prime}+F_{m \Delta t}^{\prime}$,

$R_{s}=P-F_{m \Delta t}$

$R_{g}=F_{m \Delta t}-\left(W_{m}-W_{0}\right)$

Where $R_{S}$ is the surface runoff, $R_{g}$ is the ground water runoff.

The benefits of using this semi-distributed hydrological model can be summarized as follows: 1) The input data are easily prepared. The needed hydrometeorological data are obtained from rain gauging stations, hydrological stations and meteorological stations within and around the studied catchment, and the required remote sensing data, NDVI, DEM can be freely downloaded from the internet. 2) The PET calculated by the two-source PET model replaced the pan evaporation data as the input data, which can reveal the influence of vegetation types on PET. 3) Both infiltration excess runoff mechanism and saturation excess runoff mechanism are taken into account through the hybrid runoff model, which is useful to describe the runoff generation more reasonably in the semi-arid region. In the former study, the hybrid runoff model has been successfully applied in this studied catchment, which had better performance of runoff simulation. Thus this semi-distributed hydrological model can be used to address the effect of LULC changes on the componets of hydrological cycle. 


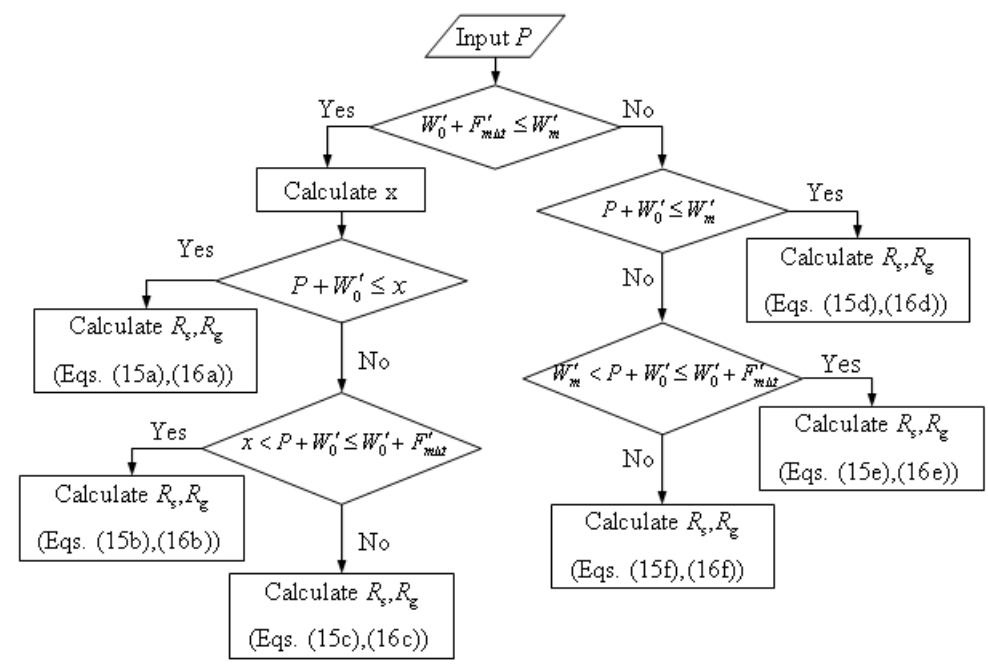

Fig. 6. Flow chart of runoff computation in HYB.

\section{Model calibration and validation}

The results of model calibration during the 4 periods using the corresponding hydrometeorological data and LULC data are shown in Table 1. Since the hybrid runoff model is a conceptual hydrological model, 11 parameters used in the model had to be optimized through model calibration against observed hydrological responses in the catchment. WUM, WLM and WDM are tension water capacities of upper, lower and deeper layer, respectively. The sum of WUM, WLM and WDM is the areal mean tension water storage capacity, affected by climate and depth of the soil. $b$, the exponential value of the tension water storage capacity curve, represents the heterogeneity of the spatial distribution of soil tension water storage capacity. The larger value of $b$ means the more remarkable heterogeneity of the spatial distribution of soil tension water storage capacity. $f_{0}, f_{c}$ and $k$ are the parameters of Horton infiltration equation $f_{t}=f_{c}+\left(f_{0}-f_{c}\right) \exp$ $(-k t)$. Where $f_{0}$ is the maximum infiltration rate, $f_{c}$ is the static infiltration rate, and $\mathrm{k}$ is decay coefficient with time. $f_{0}$ is affected by the soil texture and LULC, which is a sensitive parameter. $B X$, the exponential of infiltration capacity curve, represents the heterogeneity of the spatial distribution of soil infiltration capacity. The larger $B X$ means the more heterogeneous the spatial distribution of soil infiltration capacity is. $\mathrm{kg}$ is the recession constant of groundwater storage, which is affected by geological condition in the catchment. $\mathrm{Ke}$ and $\mathrm{Xe}$ are parameters of the Muskingum-Cunge method. $K e$ is the ratio of storage to discharge within the stream segment with the time dimension of $24 \mathrm{~h}$ under the daily simulation. $\mathrm{Xe}$ is the proportional coefficient of discharge at upstream/downstream, ranging from 0 to 0.5 . The performance of the model is measured on a daily time step using the Nash-Sutcliffe efficiency (DC, Eq. 17) and relative error (Bias, Eq. 18).
Table 1. Calibrated parameter values for the daily runoff simulation.

\begin{tabular}{lcccc}
\hline & 1964-1979 & 1980-1989 & 1990-1999 & 2000-2005 \\
\hline WUM (mm) & 20 & 20 & 20 & 20 \\
WLM $(m m)$ & 80 & 80 & 80 & 80 \\
WDM (mm) & 40 & 40 & 40 & 40 \\
$B$ & 0.22 & 0.17 & 0.25 & 0.16 \\
$B X$ & 0.25 & 0.32 & 0.2 & 0.15 \\
$f_{0}(\mathrm{~mm} / \mathrm{h})$ & 21 & 20 & 23 & 30 \\
$f_{c}(\mathrm{~mm} / \mathrm{h})$ & 3 & 3 & 3 & 3 \\
$k$ & 0.2 & 0.39 & 0.18 & 0.1 \\
$k g$ & 0.88 & 0.94 & 0.94 & 0.92 \\
$K e(h r)$ & 25 & 26 & 27 & 27 \\
$X e$ & 0.26 & 0.33 & 0.15 & 0.16 \\
\hline
\end{tabular}

$D C=1-\frac{\sum_{i=1}^{N}\left(Q_{\mathrm{obs}_{i}}-Q_{\text {sim }_{\mathrm{i}}}\right)^{2}}{\sum_{i=1}^{N}\left(Q_{\mathrm{obs}_{i}}-\overline{Q_{\mathrm{obs}}}\right)^{2}}$

$\operatorname{Bias}=\frac{\sum_{i=1}^{N} Q_{\operatorname{sim}_{i}}-\sum_{i=1}^{N} Q_{\mathrm{obs}_{i}}}{\sum_{i=1}^{N} Q_{\mathrm{obs}_{i}}} \times 100 \%$

where $Q_{\text {obsi }}$ is the observed streamflow $\left(\mathrm{m}^{3} / \mathrm{s}\right)$ at time step $i, Q_{\text {sim }_{\mathrm{i}}}$ is the simulated streamflow $\left(\mathrm{m}^{3} / \mathrm{s}\right)$ at time step $i$, $\overline{Q_{\text {obs }}}$ is the mean of the observed values $\left(\mathrm{m}^{3} / \mathrm{s}\right)$, and $N$ is the number of data points.

In Table 2, the best performance appears for the period of 1964-1979, while during the period of 2000-2003, the simulated discharge is much larger than the observed one. In the Laohahe Catchment, the effect of human activities on streamflow has intensified since 1980's. Ren et al. (2002) found that 
Table 2. Model performance during different periods

\begin{tabular}{lcccccccc}
\hline & \multicolumn{2}{c}{$1964-1979$} & \multicolumn{2}{c}{$1980-1989$} & \multicolumn{2}{c}{$1990-1999$} & $2000-2005$ \\
\cline { 2 - 8 } Period & $\begin{array}{c}\text { 1964 to 1973 } \\
\text { (calibration) }\end{array}$ & $\begin{array}{c}1974 \text { to 1979 } \\
\text { (validation) }\end{array}$ & $\begin{array}{c}1980 \text { to 1985 } \\
\text { (calibration) }\end{array}$ & $\begin{array}{c}1986 \text { to } 1989 \\
\text { (validation) }\end{array}$ & $\begin{array}{c}1990 \text { to 1995 } \\
\text { (calibration) }\end{array}$ & $\begin{array}{c}1996 \text { to 1999 } \\
\text { (validation) }\end{array}$ & $\begin{array}{c}\text { 2000 to 2003 } \\
\text { ( calibration) }\end{array}$ & $\begin{array}{c}2004 \text { to 2005 } \\
\text { (validation) }\end{array}$ \\
\hline$Q_{\text {obs }}(\mathrm{mm})$ & 408.11 & 311.26 & 86.03 & 105.72 & 314.84 & 131.38 & 26.51 & 32.19 \\
$Q_{\text {sim }}(\mathrm{mm})$ & 399.69 & 321.98 & 73.95 & 117.06 & 340.09 & 121.27 & 55.53 & 31.98 \\
Bias $(\%)$ & -2.06 & 3.45 & -14.04 & 10.73 & 8.02 & -7.69 & 109.5 & -0.64 \\
$D C$ & 0.685 & 0.739 & 0.587 & 0.639 & 0.29 & 0.637 & -0.592 & 0.867 \\
\hline
\end{tabular}

* $Q_{\mathrm{obs}}$ is the observed discharge; $Q_{\text {sim }}$ is the simulated discharge.

the amount of streamflow in northern China has a decreasing tendency in terms of natural basins and administrative regions. The annual precipitation series has yearly fluctuation but no remarkable decreasing tendency during the period of 1964-2005 in the Laohahe Catchment, thus the water use by increasing abstraction from river channels and groundwater aquifers for rice cultivation may be the primary reason for the decrease of streamflow. Figure 7 shows the comparison of the observed and simulated streamflow in 1979.

The AET was also calculated using water balance equation and compared with that simulated by using the hybrid runoff model. Table 3 and Fig. 8 compare the AET calculated directly from precipitation minus runoff and the evaporation with the model simulation. It can be seen that the results of AET simulation are realistic and acceptable.

\section{Results and discussion}

\subsection{LULC changes since 1980}

For the application of the semi-distributed hydrological model, the original LULC data were upscaled to the resolution of $30 \mathrm{~s}$ and reclassified. These processes reduced the precision of LULC data at a certain extent.

The percentages of the main vegetation types from 4 LULC scenarios are shown in Table 4 which displays important changes in LULC during the period of interest. The main LULC types are forest land, grass land and crop land, which account for more than $95 \%$ of the total area. The variation of LULC in Laohahe Catchment is complex from 1980 to 1999 , and it is difficult to discern a consistent trend of change. However, the forest land increased from $25.9 \%$ of the area in 1980 to $31.6 \%$ in 1996, up to the maximum percentage since 1980; the grass land decreased from $29.1 \%$ of the area in 1980 to $16.1 \%$ in 1996 , down to the minimum percentage since 1980; Similarly, the crop land increased from $42.7 \%$ of the area in 1980 to $48 \%$ in 1996, up to the maximum percentage since 1980. Thus the effect of LULC changes on the green water and blue water can be more obviously detected by comparing the 1996 LULC scenario with other scenarios.

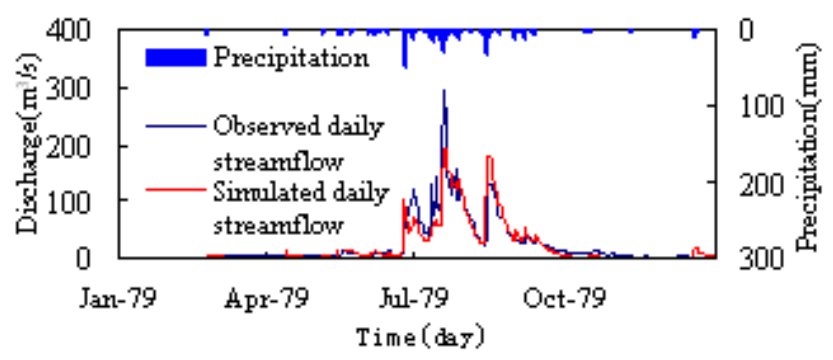

Fig. 7. Comparison of the observed and simulated daily streamflow at the Taipingzhuang station.

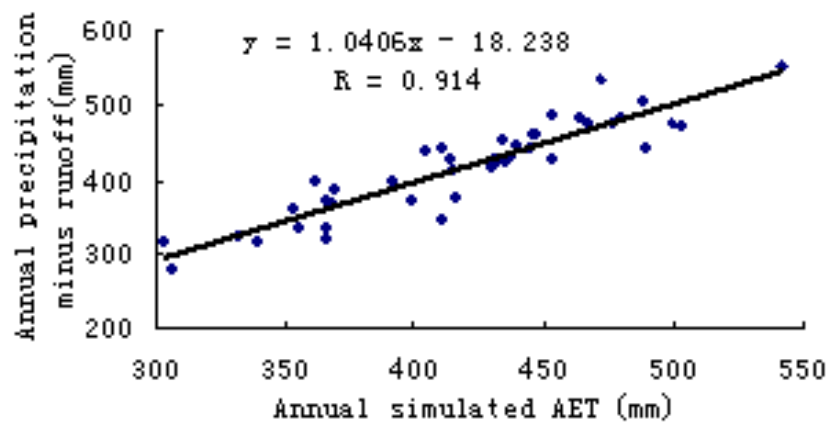

Fig. 8. Scatter plots and correlation coefficient of annual AET calculated directly from precipitation minus runoff and that simulated by using the hydrological model.

\subsection{Quantitative effect of LULC changes on green water}

Daily direct evaporation from the intercepted water $\left(E_{i}\right)$, potential canopy transpiration $\left(E_{p c}\right)$ and potential soil evaporation $\left(E_{p s}\right)$ for 4 periods were computed using the two-source PET model under 4 LULC scenarios. Table 5 presents the calculated mean annual values. In Table 5, the shaded portions show the results that were calculated from the corresponding LULC data and hydrometeorological data. PET is equal to the sum of direct evaporation from the intercepted water, potential canopy transpiration and potential soil evaporation. Incoming rainfall is partitioned into green water and blue water in the hydrological cycle. LULC characteristics can influence the rainfall partition. 
Table 3. Validation of simulated AET using the long-term water balance equation.

\begin{tabular}{lllll}
\hline Period & $1964-1979$ & $1980-1989$ & $1990-1999$ & $2000-2005$ \\
\hline Mean annual precipitation $(\mathrm{mm})$ & 459.7 & 408.3 & 497.5 & 423.2 \\
Mean annual observed runoff $(\mathrm{mm})$ & 44.96 & 19.17 & 44.61 & 9.78 \\
Mean annual precipitation minus runoff $(\mathrm{mm})$ & 414.74 & 389.13 & 452.89 & 413.42 \\
Mean annual Ea by model simulation $(\mathrm{mm})$ & 423.2 & 392.9 & 449.4 & 399.6 \\
Relative error (\%) & 2.04 & 0.97 & -0.77 & -3.34 \\
\hline
\end{tabular}

Comparing the shaded results for the period of 19641979 and period 1990-1999, the mean annual PET for the latter period is larger than that for the former period by $12.2 \mathrm{~mm}$. Comparing the results for the period of 1964-1979 and period of 1990-1999 both under the 1980 LULC scenario, the latter period mean annual PET is larger than the former one only by $0.9 \mathrm{~mm}$, which would be due to the variation of meteorological condition. Comparing the results for the period of 1990-1999 under the 1980 and 1996 LULC scenarios respectively, the latter mean annual PET is larger than the former one by $11.3 \mathrm{~mm}$. This difference is caused by LULC changes. According to above analysis, LULC changes may be the dominant factor of the PET change between the periods of 1964-1979 and 1990-1999. Comparing the results during the period of 1964-1979 under the 1980 and 1996 LULC scenarios, the latter mean annual interception evaporation is larger than the former one by $18.3 \mathrm{~mm}$, and the latter mean annual potential canopy transpiration is larger than the former one by $69.3 \mathrm{~mm}$, the latter mean annual potential soil evaporation is smaller than the former one by $73.7 \mathrm{~mm}$ and the latter mean annual AET is larger than the former one by $4 \mathrm{~mm}$. From 1980 to 1996, the forest land increased from $25.9 \%$ to $31.6 \%$, the grass land decreased from $29.1 \%$ to $16.1 \%$, and the crop land increased from $42.7 \%$ to $48 \%$ (Table 4). Thus the change of grass land into forest land and crop land in the Laohahe Catchment caused the increment in mean annual interception evaporation and potential canopy transpiration, the reduction in mean annual potential soil evaporation, and the increment in mean annual PET and AET. Similar results were obtained for changing the present land use into the scenario for natural conditions with complete tree cover by Ott and Uhlenbrook, (2004). Similarly comparing the results over the period of 1990-1999 under the 1996 and 1999 LULC scenarios, one can conclude that the change of forest land and crop land into grass land in the Laohahe Catchment caused the reduction in mean annual interception evaporation and potential canopy transpiration, the increment in mean annual potential soil evaporation, but the reduction in mean annual PET and AET.

More than $90 \%$ of precipitation in the Laohahe Catchment was consumed by evaporation. It is well known that the dominating factors of AET are PET and available water (precipitation in a catchment). In the Laohahe Catchment precipitation is much smaller than the PET in yearly time scale.

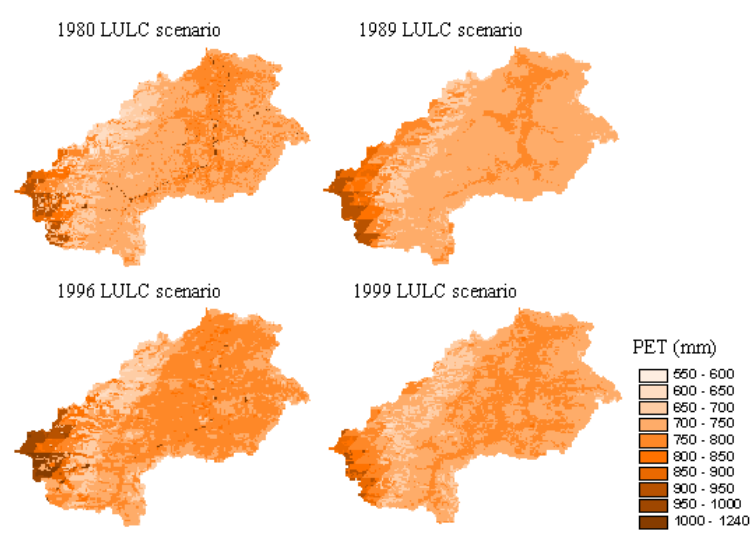

Fig. 9. Spatial distribution of mean annual PET over the period of 1980-1989 under 4 LULC scenarios

That is to say that the AET is mainly limited by the precipitation, and the degree of change of AET attributed to LULC changes is slighter than that of PET in the Laohahe Catchment. On the contrary changes in interception evaporation, and soil evaporation and plant transpiration also reduced the change of the simulated AET under different LULC scenarios. For example, as LULC changed from 1980 to 1996, as a result of the grass land changing into forest land and crop land in the catchment, the interception evaporation during period of 1964-1979 increased by $18.3 \mathrm{~mm}$, but the soil evaporation and plant transpiration decreased by $14.3 \mathrm{~mm}$. Thus the AET during the period of 1964-1979 only increased by $4 \mathrm{~mm}$, as LULC changed from 1980 to 1996.

Comparing Fig. 9 with Fig. 3, the distribution of mean annual PET is greatly influenced by the LULC data. The area with forest land can have a larger mean annual PET, and the area with the grass land can have a smaller mean annual PET over the Laohahe Catchment. Taking the 1989 LULC scenario as an example, the mean annual PET of forest land, grass land and crop land over the period of 1980-1989 was $813.0 \mathrm{~mm}, 723.0 \mathrm{~mm}$ and $751.5 \mathrm{~mm}$, respectively. Comparing Fig. 10 with Fig. 11, the spatial distribution of mean annual AET was strongly controlled by the precipitation data. The differences among the 4 plots in Fig. 10 are caused by LULC changes. The effect of LULC changes on AET did occur in some parts. 

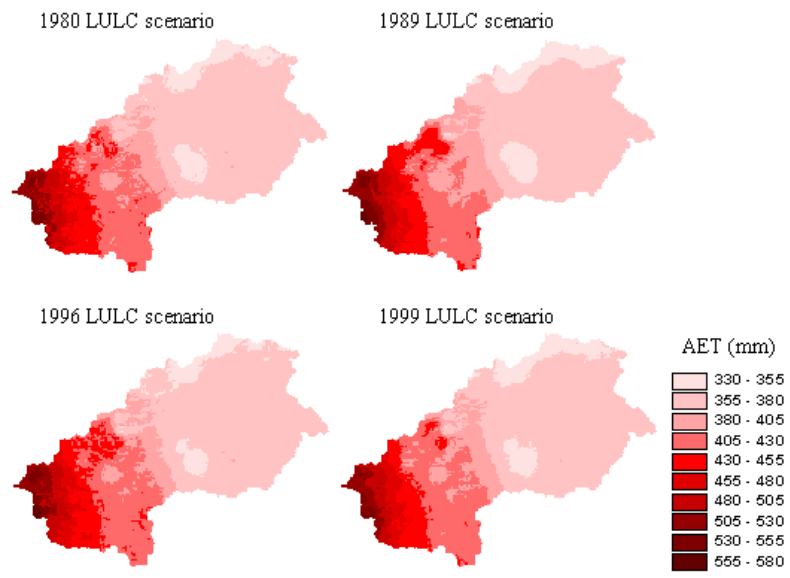

Fig. 10. Spatial distribution of mean annual AET over the period of 1980-1989 under different LULC scenarios.

Table 4. LULC changes in the Laohahe Catchment for the period of 1964-2005.

\begin{tabular}{lllll}
\hline & \multicolumn{4}{c}{ Percentage (\%) } \\
\cline { 2 - 5 } Classification & 1980 & 1989 & 1996 & 1999 \\
\hline Forest land & 25.9 & 16.9 & 31.6 & 10.5 \\
Grass land & 29.1 & 66.8 & 16.1 & 46.5 \\
Crop land & 42.7 & 16.1 & 48 & 42.9 \\
Urban & 0.6 & 0.2 & 1.9 & 0.1 \\
Others & 1.7 & 0 & 2.4 & 0 \\
\hline
\end{tabular}

\subsection{Quantitative effect of LULC changes on blue water}

Due to the difference in the speed of flow movement, runoff components are divided into surface runoff (fast flow) and groundwater runoff (slow flow) in this semi-distributed hydrological model. Blue water defined as above is surface or groundwater runoff moving above and below the ground, respectively. Daily runoff for the period of 1964-2005 was simulated by the semi-distributed hydrological model under the 4 LULC scenarios. Table 6 presents the simulated mean annual surface runoff, groundwater runoff and total runoff during each period under those 4 LULC scenarios. The observed annual precipitation and runoff during the 4 periods are shown in Table 7.

The shaded portions in Table 6 are the results that were simulated through the corresponding LULC data and hydrometeorological data. The simulated surface runoff is only about $13 \%$ of the total runoff during the period of 19642005. The effect of LULC changes on the blue water (runoff) is contrary to the green water (ET), because the sum of green water and blue water should be equal to the incoming rainfall in the hydrological cycle from an average viewpoint.

As LULC changed from 1980 to 1996, with the grass land changing into forest land and crop land in the catchment, not
Table 5. Mean annual PET under 4 LULC scenarios during different periods (Unit: $\mathrm{mm}$ )

\begin{tabular}{llllll}
\hline \multirow{2}{*}{ Period } & & \multicolumn{3}{l}{ LULC scenario } & \\
\cline { 3 - 6 } & & 1980 & 1989 & 1996 & 1999 \\
\hline \multirow{4}{*}{$1964-1979$} & $E_{i}$ & 40.1 & 36.8 & 58.4 & 39.1 \\
& $E_{p c}$ & 135.5 & 118.2 & 204.8 & 138.2 \\
& $E_{p s}$ & 563.8 & 581.5 & 490.1 & 557.1 \\
& PET & 739.4 & 736.5 & 753.3 & 734.4 \\
& AET & 423.2 & 423.8 & 427.2 & 422.5 \\
& $E_{i}$ & 38.0 & 34.5 & 55.4 & 37.0 \\
& $E_{p c}$ & 133.9 & 117.9 & 202.0 & 135.7 \\
$1980-1989$ & $E_{p s}$ & 571.9 & 590.6 & 498.3 & 566.8 \\
& PET & 743.7 & 742.9 & 755.8 & 739.4 \\
& AET & 392.3 & 392.9 & 394.6 & 392.3 \\
& $E_{i}$ & 39.5 & 35.9 & 57.9 & 38.0 \\
& $E_{p c}$ & 136.8 & 118.6 & 205.9 & 139.2 \\
& $E_{p s}$ & 564.1 & 584.3 & 487.9 & 558.7 \\
& PET & 740.3 & 738.9 & 751.6 & 735.9 \\
& AET & 445.9 & 446.5 & 449.4 & 445.0 \\
& $E_{i}$ & 35.0 & 31.8 & 51.5 & 33.9 \\
& $E_{p c}$ & 130.0 & 114.5 & 195.1 & 131.1 \\
& $E_{p s}$ & 583.9 & 604.9 & 507.9 & 580.2 \\
& PET & 748.9 & 751.2 & 754.8 & 745.2 \\
& AET & 399.6 & 400.0 & 401.1 & 399.6 \\
\hline \multirow{1}{*}{ 2000-2005-1999 }
\end{tabular}

only surface runoff but also groundwater runoff decreased during the period of 1964-1979 (Fig. 12) . The quantitative changes in LULC from 1980 to 1996 are that the grass land decreased by $1004 \mathrm{~km}^{2}$, the forest land increased by $440 \mathrm{~km}^{2}$ and the crop land increased by $409 \mathrm{~km}^{2}$. The runoff ratio decreased from 0.0981 to 0.0896 . When LULC changed from 1980 to 1999 , with the forest land changing into the grass land in the catchment, surface runoff and groundwater runoff increased for the period of 1964-1979. The quantitative changes in LULC from 1980 to 1999 are that grass land increased by $1343 \mathrm{~km}^{2}$, forest land decreased by $1189 \mathrm{~km}^{2}$, and crop land increased by $15 \mathrm{~km}^{2}$. The runoff ratio increased from 0.0981 to 0.0995 , increased only by $1.4 \%$. From above analysis, one can detect that the effect of LULC changes on runoff is non-linear.

Figure 13 shows the spatial distribution of mean annual runoff depth over the period of 1980-1989 under 4 LULC scenarios. The differences among the 4 plots in the Fig. 13 are caused by the LULC change. Runoff generation is a very complex process, which can be affected by many factors, such as climate, topography, land use, and so on. Although it can be seen that the precipitation was major influencing factor for the spatial distribution of mean annual runoff depth, the effect of LULC changes on runoff did occur in some parts.

Table 7 shows that the change in runoff ratio in the study area is significant during 1964-2005. The observed hydrological data indicates that there is an decreasing tendency in the observed annual runoff series, while there is no 
Table 6. Simulated mean annual runoff during each period under the 4 LULC scenarios.

\begin{tabular}{|c|c|c|c|c|c|}
\hline \multirow[t]{2}{*}{ Period } & \multirow[t]{2}{*}{ Item } & \multicolumn{4}{|c|}{ LULC scenario } \\
\hline & & 1980 & 1989 & 1996 & 1999 \\
\hline \multirow[t]{4}{*}{ 1964-1979 } & Surface runoff $(\mathrm{mm})$ & 7.23 & 7.22 & 6.91 & 7.30 \\
\hline & Groundwater runoff (mm) & 37.86 & 37.22 & 34.25 & 38.41 \\
\hline & Total runoff $(\mathrm{mm})$ & 45.10 & 44.45 & 41.17 & 45.73 \\
\hline & Runoff ratio & 0.0981 & 0.0967 & 0.0896 & 0.0995 \\
\hline \multirow[t]{4}{*}{ 1980-1989 } & Surface runoff $(\mathrm{mm})$ & 3.98 & 3.95 & 3.69 & 4.05 \\
\hline & Groundwater & 15.66 & 15.14 & 13.72 & 15.54 \\
\hline & Total runoff $(\mathrm{mm})$ & 19.64 & 19.10 & 17.41 & 19.60 \\
\hline & Runoff ratio & 0.0473 & 0.0460 & 0.0419 & 0.0472 \\
\hline \multirow[t]{4}{*}{ 1990-1999 } & Surface runoff ( & 2.95 & 2.95 & 2.82 & 2.99 \\
\hline & Groundwater runoff (mm) & 46.78 & 46.18 & 43.30 & 47.60 \\
\hline & Total runoff $(\mathrm{mm})$ & 49.75 & 49.14 & 46.14 & 50.61 \\
\hline & Runoff ratio & 0.1000 & 0.0987 & 0.0927 & 0.1017 \\
\hline \multirow[t]{4}{*}{$2000-2005$} & Surface runoff $(\mathrm{mm})$ & 0.78 & 0.78 & 0.76 & 0.79 \\
\hline & Groundwater runoff (mm) & 13.70 & 13.34 & 12.69 & 13.80 \\
\hline & Total runoff $(\mathrm{mm})$ & 14.49 & 14.13 & 13.45 & 14.59 \\
\hline & Runoff ratio & 0.0342 & 0.0334 & 0.0318 & 0.0345 \\
\hline
\end{tabular}

Table 7. Annual mean precipitation and runoff during those 4 periods.

\begin{tabular}{lllll}
\hline & $1964-1979$ & $1980-1989$ & $1990-1999$ & $2000-2005$ \\
\hline Precipitation (mm) & 459.7 & 408.3 & 497.5 & 423.2 \\
Observed Runoff (mm) & 44.96 & 19.17 & 44.61 & 9.78 \\
Runoff ratio & 0.0978 & 0.0470 & 0.0897 & 0.0231 \\
\hline
\end{tabular}

decreasing trend in the series of annual precipitation in the catchment during the period of 1964-2005. These two phenomena resulted in a decrease in the runoff ratio in the studied area during 1964-2005. Based on the long-term water balance equation $R=P-E$, the increased evaporation is the direct cause of runoff decrease. Water resources are mainly subjected to climatic circumstances and land surface characteristics. With the socioeconomic development, the amount of runoff is to some extent influenced by human activities, such as agricultural production, industrial development, and municipal construction, etc. Since 1949, the population, livestock, food production and GDP have increased tremendously in the Chifeng City which is the main city in the Laohahe Catchment (Fig. 14). The steep rise in food production and GDP occurred since 1978, because of the implementation of the policy of China's reform and opening to the world. All of these changes can cause the increase of surface water use and groundwater exploitation, especially, water is drawn from river channel for cropland irrigation, industrial production and municipal utilization within or out of the studied catchment. Besides these, the LULC changes could cause the change of the PET in the catchment, consequently affect the evaporation from the land surface to the atmosphere.

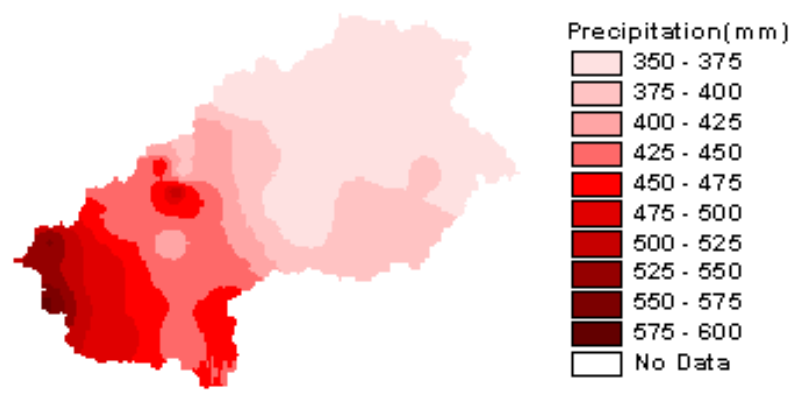

Fig. 11. Spatial distribution of mean annual precipitation over the period of 1980-1989

\section{Conclusions and suggestions}

The purpose of this study was to assess the quantitative effect of LULC changes on green water and blue water in the Laohahe Catchment using a semi-distributed hydrological model coupled with a two-source PET model. The observed daily hydrometeorological data from 1964 to 2005 was divided into 4 periods: 1964-1979, 1980-1989, 1990-1999, and 2000-2005. The LULC scenarios for those four periods were developed using the LULC data in 1980, 1989, 1996, and 1999, respectively. The variation of LULC in the Laohahe Catchment is complex from 1980 to 1999 . The forest land decreased from $25.9 \%$ of the area in 1980 to $10.5 \%$ in 1999 , however the forest land increase to $31.6 \%$ of the area in 1996.

Model calibration for those 4 periods using the corresponding hydrometeorological data and LULC data was initially carried out. The proportions of surface runoff and 

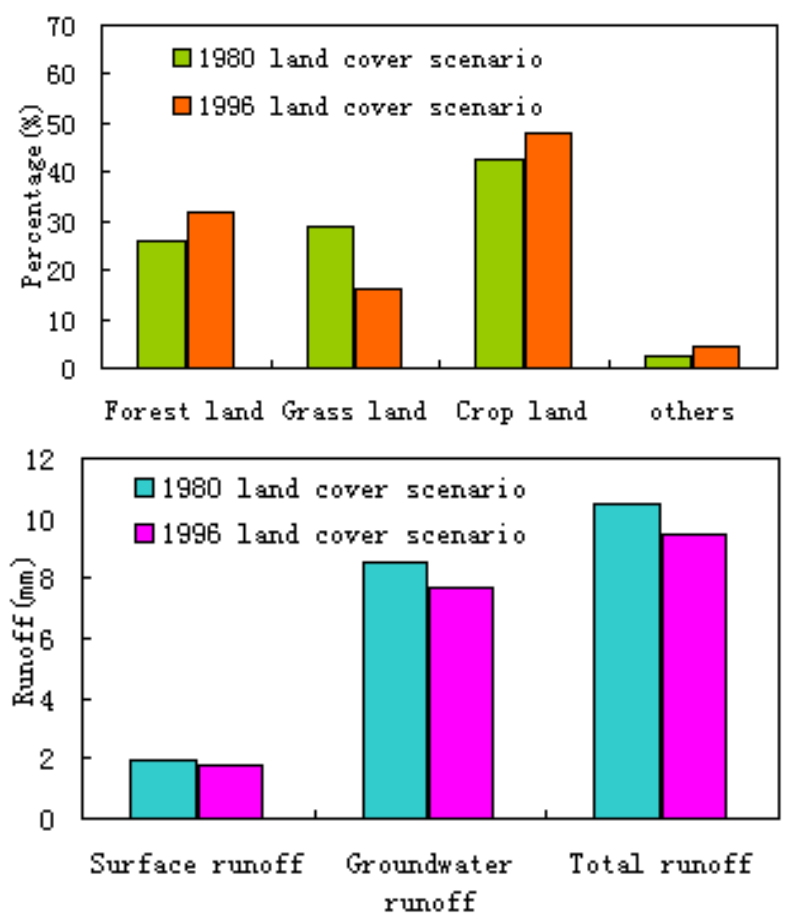

Fig. 12. (a) LULC changed from 1980 to 1996; (b) Simulated mean annual runoff during the period of 1964-1979 under the 1980 and 1996 LULC scenarios.
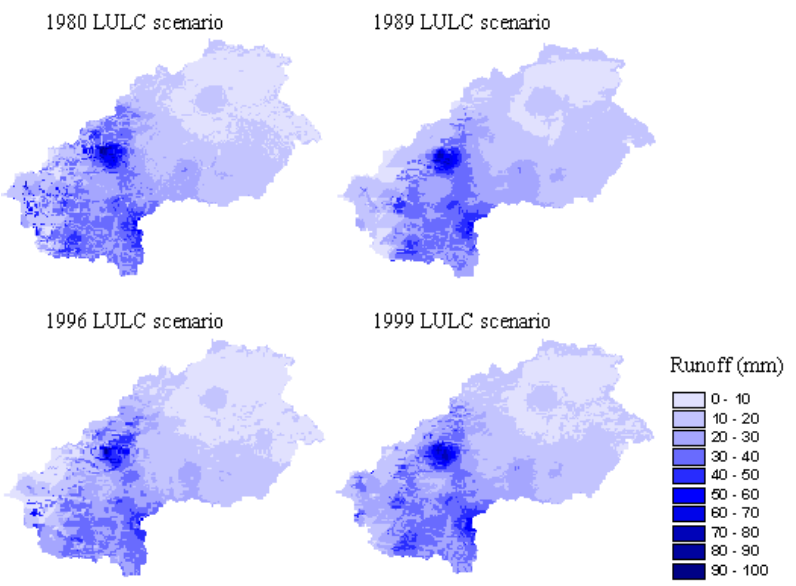

Fig. 13. Spatial distribution of mean annual runoff depth over the period of 1980-1989 under different LULC scenarios

groundwater runoff simulated indicated that the saturation runoff generation was dominant in the Laohahe Catchment. It is suggested that runoff generation mechanisms would be investigated in depth according to soil hydraulic parameters, if soils data within the catchment are available.

The annual interception evaporation, potential canopy transpiration, potential soil evaporation and AET during 4 periods under each LULC scenario show that the LULC
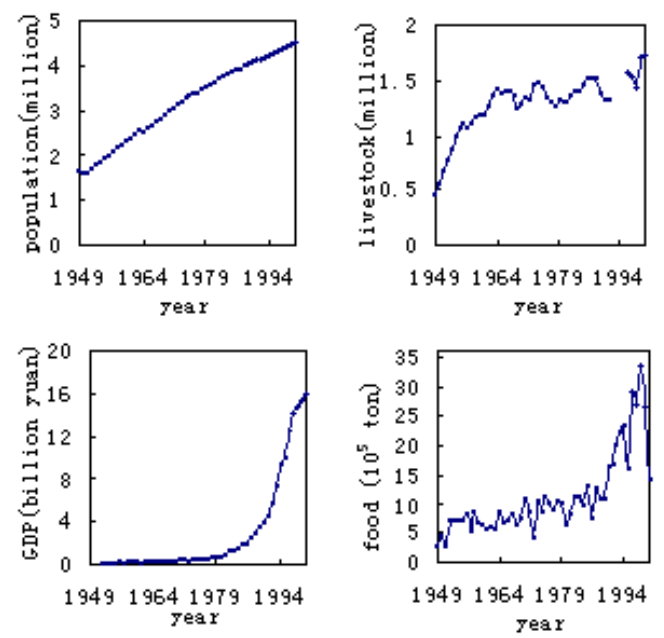

Fig. 14. Changes of population, livestock, GDP and food production in the Chifeng City during the period of 1949-2000.

change is the dominant factor for the change of PET between the periods of 1964-1979 and 1990-1999, and the change of grass land into forest land and crop land in the Laohahe Catchment caused the increment in annual interception evaporation and potential canopy transpiration, the reduction in annual potential soil evaporation, and the increment in mean annual PET and AET. When LULC changed from 1980 to 1996, the green water (ET) during the period of 1964-1979 was increased by $0.95 \%$. The distribution map of mean annual PET over the Laohahe Catchment showed that the area with forest land can have a larger mean annual PET, and the area with the grass land can have a smaller mean annual PET. The spatial distributions of mean annual AET and runoff depth were mainly influenced by precipitation, however, the effect of LULC changes on AET and runoff does exist in some parts of the study catchment. The effect of LULC changes on the blue water (runoff) is contrary to that on the green water (ET). When LULC changed from 1980 to 1996 , the blue water during the period of $1964-1979$ was decreased by $8.71 \%$.

In general, the change of LULC condition is not continuous, and is small in consecutive years. However, the change is quite large on a decadal basis. In this study, according to the availability of LULC data, four scenarios of LULC were selected for representing the vegetation cover over the studied area during four different periods. This presentation has error, to some extent. The analyses remarked above imply that four scenarios can represent the situation of LULC in the corresponding periods, respectively. Excluding the input data error, the model parameters equifinality problem, simplifications inherent in the model structure and mathematical descriptions of various processes could lead to the uncertainty of model results (Ott and Uhlenbrook, 2004). In order to obtain more accurate, reliable model results, more 
spatially and temporally distributed data (LULC data, meteorological data) should be obtained through remote sensing or field investigation, and the hydrological physical processes (ET, infiltration, runoff generation and runoff concentration) should be understand further, especially in the semi-arid area. Although the semi-distributed hydrological model used in this study is not ideal enough and need to be improved, it has capability to quantify the effects of LULC changes on green and blue waters. This study investigated the effect of LULC changes on ET and runoff. The conclusions form an important basis for the study of land use management, integrated water resources management, drought, and so on.

Acknowledgements. This study was supported by the National Key Basic Research Program of China (2006CB400502). This work was financially supported by Special Basic Research Fund for Methodology in Hydrology under Grant No. 2007FY140900, Ministry of Sciences and Technology, China, the 111 Project under Grant B08048, Ministry of Education and State Administration of Foreign Experts Affairs, China. This research was also supported by the Program for Changjiang Scholars and Innovative Research Team in University (IRT0717), Ministry of Education, China and the Grand Sci-Tech Research Project of Ministry of Education (308012).

\section{Edited by: S. Uhlenbrook}

\section{References}

Ashraf, M., Loftis, J., and Hubbard, K. G.: Application of geostatistics to evaluate partial weather station networks, Agr. Forest Meteorol., 84, 255-271, 1997.

Bosch, J. M. and Hewlett, J. D.: A review of catchment experiments to determine the effect of vegetation changes on water yield and evapotranspiration, J. Hydrol., 55, 3-23, 1982.

Chen, J. F. and Li, X. B.: Simulation of hydrological response to land-cover changes, Chin. J. Appl. Ecol., 15(5), 833-836, 2004.

Hibbert, A. R.: Forest treatment effects on water yield, in: International Symposiun on Forest Hydrology, edited by: Sopper, W. E. and Lull, H. W., Pergramon, Oxford, UK, p. 813, 1967.

Hollis, G. E.: The effect of urbanization on flood of different recurrence interval, Water Resour. Res., 11(3), 431-435, 1975.

$\mathrm{Hu}, \mathrm{C}$. Q.: Computational method of runoff generation in semihumid and semi-arid regions, Proceedings of the Symposium on Hydrological Information and Forecasting, China Water Power Press, Beijing, China, 57-62, 1993(in Chinese).

$\mathrm{Hu}, \mathrm{C}$. , Guo, S., Xiong, L., et al.: A modified Xinanjiang model and its application in Northern China, Nord. Hydrol., 36(2), 175192, 2005.

Falkenmark, M. and Rockstrom, J.: Balancing water for humans and nature: the new approach in ecohydrology, Earthscan, UK and USA, 247pp. 2004

FAO: World agriculture: Towards 2010. An FAO study, Food and Agriculture Organization, Rome, Italy, 463pp., 1995a

FAO: Land and water integration and river basin management, Proceedings of an informal workshop 31 January-2 February 1993, Land and Water Bulletin No. 1, Food and Agricultural Organization, Rome, Italy, 15-16, 1995b.

Lorup, J. K., Refsgaard, J. C., and Mazvimavi, D.: Assessing the effect of land use change on catchment runoff by combined use of statistical tests and hydrological modeling: case studies from Zimbabwe, J. Hydrol., 205, 147-163, 1998.

Martz, W. and Garbrecht, J.: Numerical definition of drainage network and subcatchment areas from digital elevation models, Comput. Geosciences, 18(6), 747-761, 1992.

Mo, X., Liu, S., Lin, Z., and Zhao, W.: Simulating temporal and spatial variation of evapotranspiration over the Lushi basin, J. Hydrol., 285, 125-142, 2004.

Ott B. and Uhlenbrook S.: Quantifying the impact of land-use changes at the event and seasonal time scale using a processoriented catchment model, Hydrol. Earth Syst. Sci., 8(1), 62-78, 2004.

Person R. L. and Miller L. D.: Remote mapping of standing crop biomass for estimation of the productivity of the short grass prairie, Proceeding of the 8th International Symposium on Remote Sensing of the Environment, Vol. 2, 1355-1379, 1972.

Ren, L., Wang, M., Li, C., et al.: Impacts of human activity on river runoff in the northern area of China, J. Hydrol., 261(1-4), 204-217, 2002.

Richards, J. A. and Jia, X.: Remote Sensing Digital Image Analysis, 3rd edn., Springer-Verlag, Berlin, Germany, 363 pp., 1999.

Siriwardena, L., Finlayson, B. L. and McMahon, T. A.: The impact of land use change on catchment hydrology in large catchments: The Comet River, Central Queensland, Australia, J. Hydrol., 326, 199-214, 2006.

Shuttleworth, W. J.: Evaporation, in: Handbook of Hydrology, edited by: Maidment, D. R., McGraw-Hill, New York, USA, 4.1-4.53, 1993.

Wilk, J., Andersson, L., and Plermkamon, V.: Hydrological impacts of forest conversion to agriculture in a large river basin in northeast Thailand, Hydrol. Process., 15, 2729-2748, 2001.

Yuan, F.: Hydrological process modeling considering the effect of vegetation, Ph.D. Thesis, Hohai University, China, 2006(in Chinese).

Yuan, F., Ren, L., Yu, Z., and Xu, J.: Potential evapotranspiration computation using a two-source method for the Xin'anjiang hydrological model, J. Hydrol. Eng., 13(5), 305-316, 2008.

Zhang, L., Dawes, W. R., and Walker, G. R.: Predicting the Effect of Vegetation Changes on Catchment Average Water Balance, Cooperative Research Centre for Catchment Hydrology, Clayton, Victoria, Australia, Technical Report 99/12, 35 pp., 1999.

Zhao, R. J.: The Xianjiang model applied in China, J. Hydrol., 135(3), 371-381, 1992.

Zhao, R. J., Zhang, Y. L., Fang, L. R., Liu, X. R. and Zhang, Q. S.: The Xinanjiang model, Proceedings of the Oxford Symposium on Hydrological Forecasting, IAHS Pub. No. 129, IAHS Press, Wallingford, UK, 351-356, 1980. 